\title{
Toxicity Evaluation by Single and Repeated Administration of Yeast Hydrolysate DNF-10
}

\author{
Yejin Ahn', Singeun Kim ${ }^{1}$, Hyung Joo Suh ${ }^{1}$, and Eun Young Jung ${ }^{2}$ \\ ${ }^{1}$ Department of Integrated Biomedical and Life Science, Graduate School, Korea University, Seoul 02841, Korea \\ ${ }^{2}$ Department of Home Economic Education, Jeonju University, Jeonbuk 55069, Korea
}

\begin{abstract}
This study aimed at investigating the acute and subacute oral toxicity of yeast hydrolysate (DNF-10) in Sprague-Dawley rats. To determine the acute toxicity of DNF-10, it was orally administered to rats at a dose of 5,000 mg/ $\mathrm{kg}$. Furthermore, to determine subacute toxicity of DNF-10, it was orally administered to female and male rats at a dose of $1,000 \mathrm{mg} / \mathrm{kg}$ for 90 days. In the acute toxicity test, the experimental group did not show changes in body and organ weights compared to the corresponding weights in the control group. When compared to female controls, the DNF-10treated female rats showed decreased red blood cell counts, haemoglobin, and total bilirubin levels; however, the parameters remained within the normal range. In the subacute toxicity test, DNF-10 administration significantly reduced body weight among male rats, which appears attributable to the anti-obesity effect of the compound. In the experimental groups, significant differences in some haematological parameters were considered as non-toxic because the results were within the normal range. These results suggest that DNF-10 is safe and non-toxic at single doses $(5,000 \mathrm{mg} / \mathrm{kg})$ and repeated doses $(1,000 \mathrm{mg} / \mathrm{kg})$.
\end{abstract}

Keywords: acute toxicity, Saccharomyces cerevisiae, subacute toxicity, yeast hydrolysate

\section{INTRODUCTION}

Protein hydrolysates are obtained by decomposing proteins using acids, enzymes, and other physicochemical methods, and are used as food additives. They are categorized into hydrolysed vegetable proteins, which are made mainly from soybeans and hydrolysed animal proteins, which are mostly derived from fish and meat. Protein hydrolysates are composed of complexes such as peptides and amino acids with small molecular weights due to protein breakdown. Therefore, they are quickly absorbed, easily digested, and used for various food-related purposes. Because of the varied functions of protein hydrolysates, research into functional protein hydrolysates is being actively conducted (Ozuna et al., 2015).

Research into single-cell proteins as a protein source has been undertaken, and yeast has attracted attention as the most suitable protein supply. Yeast is one of the most commercially used fungi; it has been proven to be safe and is useful in brewing, wine manufacturing, and bakery industries (Lazo-Vélez et al., 2018; Parapouli et al., 2020). It has traditionally been used for fermentation in the brewing and bakery industry. However, its uses in biochemical and medical applications have been limited due to difficulties in physiological activity. Since 2000, interest in yeast hydrolysates obtained by treatment with proteolytic enzymes has attracted new attention. In general, yeast hydrolysates produced from baker's yeast or beer yeast by autolysis are used as nutritional supplements, food additives, and flavouring agents (Bekatorou et al., 2006). During autolysis, the effects of autolytic enzymes, including proteases, glucanases, and nucleases, result in the hydrolysis of intracellular compounds (Verduyn et al., 1999).

Yeast hydrolysates, unlike conventional yeast, have various physiological activities. In particular, yeast hydrolysates have been reported to show anti-stress results (Yu et al., 2001; Yu et al., 2002; Kim et al., 2003; Suh et al., 2008) and to improve reproductive function (Hong et al., 2004). Furthermore, yeast hydrolysates have been reported to exhibit physiological active functions through the regulation of hormones via neurotransmitter expression in the brain (Jung et al., 2009). Although previous evaluations of the safety of yeast hydrolysates have shown 
that these compounds have various physiological activities (Jung et al., 2010; Jung et al., 2011), single- and repeated-dose toxicity tests (acute and subacute toxicity tests, respectively) are required because new standards have been applied due to changes in the external environment. Therefore, this study was aimed at evaluating the safety of yeast hydrolysate, DNF-10, through single- and repeated-dose toxicity tests with doses of 5,000 and 1,000 $\mathrm{mg}$, respectively.

\section{MATERIALS AND METHODS}

\section{Yeast hydrolysate}

Saccharomyces cerevisiae was cultured according to a previously described method to recover the cells (Jung et al., 2009). To the recovered cells was added $50 \mathrm{mM}$ phosphate buffer ( $\mathrm{pH} 7.0) 10$ times the amount of the cells. Then, protease was added to $0.5 \%$ of the cells, and hydrolysis was performed at $30^{\circ} \mathrm{C}$ for $6 \mathrm{~h}$. To inactivate the enzyme, the supernatant obtained by centrifugation at $8,000 \mathrm{~g}$ after standing for $10 \mathrm{~min}$ in a water bath maintained at $100^{\circ} \mathrm{C}$ was passed through a $10 \mathrm{kDa}$ Hydrosart membrane (Sartorius Stedim Biotech GmbH, Göttingen, Germany). The peptide in the filtrate was separated, dried, and designated as yeast hydrolysate DNF-10.

\section{Animals}

Animal experiments were conducted with the approval of the Korea University Institutional Animal Care and Use Committee (KUIACUC-2020-0002). Male and female Sprague-Dawley rats (Orient Bio, Seongnam, Korea) were used. The animals were visually inspected once they were obtained, and after 1 week of quarantine and purification, animals considered to be healthy were selected and used in the experiment. The breeding environment is set to maintain at a temperature of $23 \pm 3^{\circ} \mathrm{C}$, relative humidity of $50 \pm 10 \%$, exposure to light for $12 \mathrm{~h}$ (lights on from 08:00 to 20:00 h), ventilation frequency of 10 to 20 times/h, and illuminance of 150 to 300 Lux. The animals were given unrestricted access to solid feed (PMI Nutrition International, Richmond, VA, USA), which was sterilized by irradiation. Similarly, the animals had ad libitum access to sterilized tap water, which was filtered using a microfilter and sterilized using an ultraviolet water sterilizer.

\section{Acute and subacute toxicity tests}

To evaluate the toxicity that could develop owing to single and repeated administration of test substances, toxicity tests were conducted according to the Organisation for Economic Co-operation and Development test guideline (OECD, 2002; OECD, 2018): 5,000 mg/kg and 1,000 $\mathrm{mg} / \mathrm{kg}$ for the single- and repeated-dose toxicity tests, respectively. For the single-dose acute toxicity test, the experimental animals were divided into a control group and a DNF-10 administration group; each group comprised five males and five female rats that were randomly assigned. DNF-10 toxicity was evaluated by administering it $(5,000 \mathrm{mg} / \mathrm{kg})$ once and evaluating hematologic and pathologic changes after 14 days of observation. For the repeated-dose subacute toxicity test, the experimental animals were divided into a control group and a DNF-10 administration group; each group consisted of five males and five female rats that were randomly assigned. DNF$10(1,000 \mathrm{mg} / \mathrm{kg})$ was administered once daily for 90 days. DNF-10 toxicity was determined by evaluating hematologic and pathologic changes after 14 days of observation.

\section{Blood and organ weight analyses}

For the whole blood and blood biochemical analyses, the animals were fasted for $12 \mathrm{~h}$ prior to autopsy and anaesthetised with $\mathrm{CO}_{2}$. The blood sample was collected from the abdominal aorta. The blood samples were obtained using blood collection tubes containing ethylenediaminetetraacetic acid and heparin, which are anticoagulants. The former anticoagulant was used for the whole blood sample and the latter for the plasma sample. Whole blood samples were immediately analysed using the $\mathrm{KN}-21 \mathrm{~N}$ system (Sysmex, Seoul, Korea), and the factors analysed were as follows: red blood cells (RBCs), white blood cells (WBCs), haematocrit (Hct), haemoglobin (Hb), mean corpuscular volume (MCV), mean corpuscular haemoglobin $(\mathrm{MCH})$, and mean corpuscular haemoglobin concentration (MCHC).

Plasma was centrifuged at $4^{\circ} \mathrm{C}$ and $3,000 \mathrm{rpm}$ for 15 min, separated, stored at $-70^{\circ} \mathrm{C}$ until analysis, and then subjected to a blood biochemical test. The blood biochemical test was performed using the FUJI DRI-CHEM 3500 analyser (Fuji Photo Film Co., Osaka, Japan). The parameters evaluated in the blood biochemical analysis were as follows: albumin (ALB), alanine aminotransferase (ALT), aspartate aminotransferase (AST), ammonia $\left(\mathrm{NH}_{3}\right)$, blood glucose (GLU), blood urea nitrogen (BUN), creatinine (CRE), creatine phosphokinase (CPK), highdensity lipoprotein (HDL), lactate dehydrogenase (LDH), total bilirubin (BIL), total cholesterol (TCHO), triglyceride (TG), total protein (TP), and uric acid (UA).

The animals' organs were first visually examined by excising the brain, epididymis, heart, kidney, liver, lung, ovary, spleen, testis, thyroid, and uterus. The extracted organs were treated with saline solution and their weights were measured after removing moisture. The measured organ weight was expressed as relative weight per $100 \mathrm{~g}$ body weight. 


\section{Statistical analysis}

All experimental results were expressed as mean \pm standard error of the mean (SEM) values. The statistical program Statistical Package for the Social Science (SPSS; ver. 12.0, SPSS Inc., Chicago, IL, USA) was used for all statistical analyses. The significance between the values was determined using the independent sample $t$-test.

\section{RESULTS AND DISCUSSION}

\section{Changes in body and organ weights}

No death was observed 2 weeks after the administration of a single dose of DNF-10 at 5,000 mg/ $\mathrm{kg}$ (acute toxicity test) in the experimental group (data not shown). Furthermore, no death occurred 2 weeks after the repeated administration of DNF-10 at 1,000 mg/kg for 90 days (subacute toxicity test) in the experimental group (data not shown). Symptoms such as fur loss, diarrhoea, faeces, decreased motor activity, and oedema caused by toxic substances were not observed in female and male animals after either toxicity test (data not shown).

A tendency for a gradual increase in the body weight of both male and female animals was noted at 2 weeks after the single administration of DNF-10 (5,000 mg/kg) in the experimental group (Fig. 1). However, the intergroup difference with respect to the control group was not significant (Table 1). In the subacute toxicity test, the weight of DNF-10-treated male rats at 6 weeks after oral administration of DNF-10 significantly differed from the male controls. Furthermore, the weight of DNF-10-treated female rats differed from the female controls. However, the intergroup difference was not significant (Fig. 1). When DNF-10 was repeatedly administered at $1,000 \mathrm{mg} /$ $\mathrm{kg}$ for 90 days, the weight gain in the DNF-10-treated male rats was significantly different from the male controls (Table 1). However, the weight gain of the DNF-10treated female rats decreased relative to the female controls; however, the intergroup difference was not significant.

At 2 weeks after single-dose DNF-10 administration, no unusual pathological findings were found in the organs
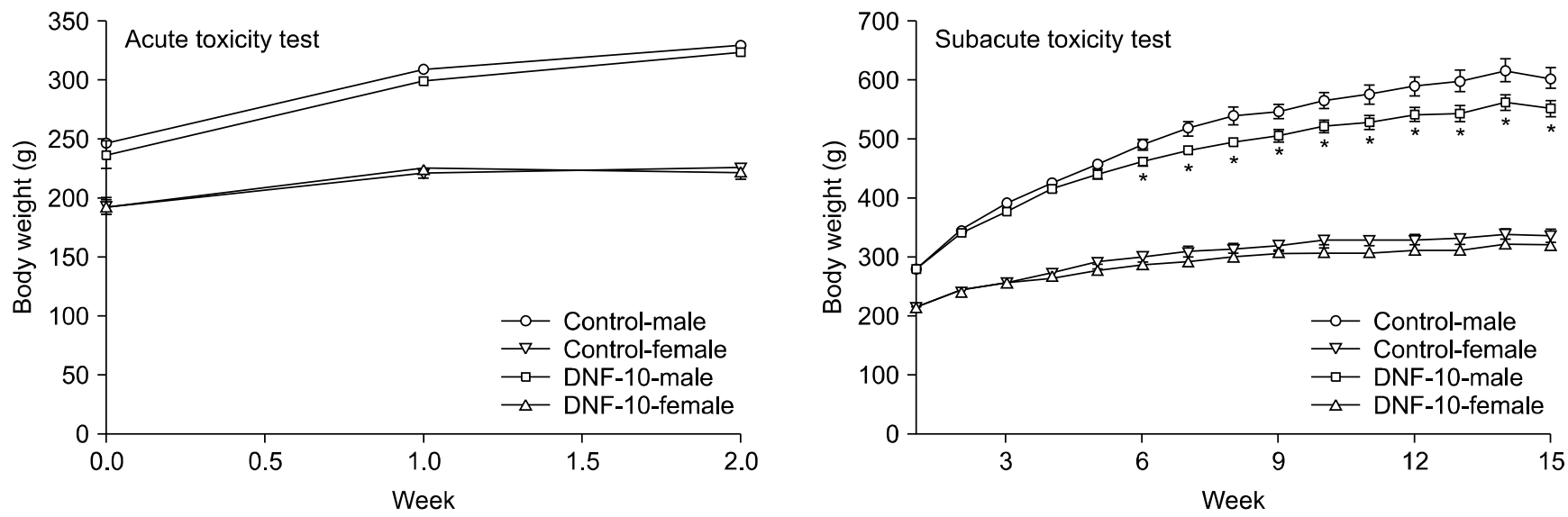

Fig. 1. Change in the body weight of Sprague-Dawley rats treated orally with DNF-10 for the determination of acute and subacute toxicity. Acute toxicity was observed for 14 days after the single administration of $5,000 \mathrm{mg} / \mathrm{kg}$ DNF-10. Subacute toxicity was observed for 14 days after the repeated administration of $1,000 \mathrm{mg} / \mathrm{kg}$ DNF-10 for 90 days. Values are mean \pm SEM for each group. Significant differences at ${ }^{*} P<0.05$ by the Student's $t$-test.

Table 1. Body weight gain and daily intake of Sprague-Dawley rats treated orally with DNF-10 for the evaluation of acute and subacute toxicity

\begin{tabular}{|c|c|c|c|c|}
\hline & \multicolumn{2}{|c|}{ Acute toxicity } & \multicolumn{2}{|c|}{ Subacute toxicity } \\
\hline & Control & DNF-10 & Control & DNF-10 \\
\hline \multicolumn{5}{|l|}{ Female } \\
\hline Body weight gain (g) & $33.23 \pm 7.40^{\mathrm{ns}}$ & $28.77 \pm 9.24$ & $122.67 \pm 7.13^{\mathrm{ns}}$ & $106.76 \pm 5.16$ \\
\hline Food intake $(\mathrm{g} / \mathrm{d})$ & $20.73 \pm 1.88^{\mathrm{ns}}$ & $21.67 \pm 0.67$ & $20.46 \pm 0.15^{\mathrm{ns}}$ & $20.64 \pm 0.50$ \\
\hline Water intake (mg/d) & $26.44 \pm 3.47^{\mathrm{ns}}$ & $29.89 \pm 3.31$ & $31.57 \pm 1.01^{\mathrm{ns}}$ & $28.55 \pm 1.73$ \\
\hline \multicolumn{5}{|l|}{ Male } \\
\hline Body weight gain (g) & $82.56 \pm 3.51^{\mathrm{ns}}$ & $86.38 \pm 11.90$ & $337.09 \pm 18.04$ & $284.07 \pm 12.91^{*}$ \\
\hline Food intake $(\mathrm{g} / \mathrm{d})$ & $31.59 \pm 2.04^{\mathrm{ns}}$ & $32.16 \pm 2.13$ & $29.27 \pm 0.47^{\text {ns }}$ & $27.71 \pm 0.16$ \\
\hline Water intake $(\mathrm{mg} / \mathrm{d})$ & $34.72 \pm 1.64^{\mathrm{ns}}$ & $34.60 \pm 2.47$ & $38.34 \pm 1.69^{\text {ns }}$ & $32.26 \pm 2.37$ \\
\hline
\end{tabular}

Values are mean \pm SEM for each group.

Significant differences at ${ }^{*} P<0.05$ by Student's $t$-test.

${ }^{\mathrm{ns}}$ Not significant. 
Table 2. Organ weights of Sprague-Dawley rats treated orally with DNF-10 for the evaluation of acute and subacute toxicity (unit: $\mathrm{g} / 100 \mathrm{~g}$ of body weight)

\begin{tabular}{|c|c|c|c|c|}
\hline \multirow{2}{*}{ Organ } & \multicolumn{2}{|c|}{ Acute toxicity } & \multicolumn{2}{|c|}{ Subacute toxicity } \\
\hline & Control & DNF-10 & Control & DNF-10 \\
\hline \multicolumn{5}{|l|}{ Female } \\
\hline Liver & $3.42 \pm 0.08^{\text {ns }}$ & $3.58 \pm 0.09$ & $2.57 \pm 0.05$ & $2.78 \pm 0.07^{*}$ \\
\hline Kidney & $0.86 \pm 0.02^{\mathrm{ns}}$ & $0.86 \pm 0.02$ & $0.60 \pm 0.02$ & $0.67 \pm 0.02^{*}$ \\
\hline Spleen & $0.21 \pm 0.01^{\mathrm{ns}}$ & $0.22 \pm 0.01$ & $0.15 \pm 0.01^{\mathrm{ns}}$ & $0.16 \pm 0.01$ \\
\hline Heart & $0.41 \pm 0.01^{\mathrm{ns}}$ & $0.44 \pm 0.01$ & $0.31 \pm 0.01^{\mathrm{ns}}$ & $0.33 \pm 0.04$ \\
\hline Lung & $0.63 \pm 0.04^{\text {ns }}$ & $0.62 \pm 0.03$ & $0.46 \pm 0.02^{\mathrm{ns}}$ & $0.53 \pm 0.03$ \\
\hline Brain & $0.81 \pm 0.03^{\mathrm{ns}}$ & $0.84 \pm 0.02$ & $0.60 \pm 0.02^{\mathrm{ns}}$ & $0.62 \pm 0.02$ \\
\hline Thyroid & $0.24 \pm 0.02^{\mathrm{ns}}$ & $0.25 \pm 0.02$ & $0.16 \pm 0.01^{\mathrm{ns}}$ & $0.17 \pm 0.01$ \\
\hline Ovary & $0.06 \pm 0.00^{\mathrm{ns}}$ & $0.06 \pm 0.00$ & $0.04 \pm 0.00^{\mathrm{ns}}$ & $0.04 \pm 0.00$ \\
\hline Uterus & $0.21 \pm 0.01^{\mathrm{ns}}$ & $0.20 \pm 0.01$ & $0.18 \pm 0.03^{\mathrm{ns}}$ & $0.22 \pm 0.02$ \\
\hline \multicolumn{5}{|l|}{ Male } \\
\hline Liver & $3.54 \pm 0.07^{\mathrm{ns}}$ & $3.52 \pm 0.12$ & $2.64 \pm 0.06^{\mathrm{ns}}$ & $2.78 \pm 0.13$ \\
\hline Kidney & $0.89 \pm 0.22^{\mathrm{ns}}$ & $0.91 \pm 0.02$ & $0.68 \pm 0.03^{\mathrm{ns}}$ & $0.69 \pm 0.02$ \\
\hline Spleen & $0.21 \pm 0.11^{\mathrm{ns}}$ & $0.21 \pm 0.01$ & $0.15 \pm 0.01^{\mathrm{ns}}$ & $0.15 \pm 0.01$ \\
\hline Heart & $0.42 \pm 0.01^{\mathrm{ns}}$ & $0.42 \pm 0.02$ & $0.32 \pm 0.01^{\mathrm{ns}}$ & $0.31 \pm 0.01$ \\
\hline Lung & $0.57 \pm 0.04^{\mathrm{ns}}$ & $0.54 \pm 0.04$ & $0.37 \pm 0.01^{\mathrm{ns}}$ & $0.41 \pm 0.02$ \\
\hline Brain & $0.62 \pm 0.01^{\mathrm{ns}}$ & $0.61 \pm 0.01$ & $0.35 \pm 0.01$ & $0.39 \pm 0.01^{* *}$ \\
\hline Thyroid & $0.18 \pm 0.01^{\mathrm{ns}}$ & $0.20 \pm 0.01$ & $0.14 \pm 0.02^{\mathrm{ns}}$ & $0.14 \pm 0.01$ \\
\hline Testis & $0.95 \pm 0.03^{\mathrm{ns}}$ & $0.96 \pm 0.03$ & $0.63 \pm 0.02^{\mathrm{ns}}$ & $0.65 \pm 0.04$ \\
\hline Epididymis & $0.13 \pm 0.01^{\mathrm{ns}}$ & $0.15 \pm 0.01$ & $0.14 \pm 0.01^{\mathrm{ns}}$ & $0.16 \pm 0.01$ \\
\hline
\end{tabular}

Values are mean \pm SEM for each group.

Significant differences at ${ }^{*} P<0.05$ and ${ }^{* *} P<0.01$, respectively by Student's $t$-test.

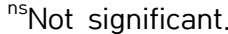

of the female and male rats in any experimental group. In addition, the organ weights of all the rats in the experimental group did not significantly differ from the corresponding values in the control group (Table 2). In the 90-day repeated-dose toxicity test, no pathological findings were found in the organs of male animal in the experimental group. However, in the male experimental group, brain weight increased significantly compared to male controls. However, the increased brain weight was still within the normal range (brain weight: 0.39 0.84 $\mathrm{g} / 100 \mathrm{~g}$ of body weight). Brain weight for female rats in the experimental group did not significantly differ from female controls (Table 2).

Even in a previous study with single-dose and repeateddose administration (for 14 days) of the test compound, intergroup differences in weight gain, dietary intake, and drinking water intake were not significant. Furthermore, in the subacute toxicity test, the weight gain in the male rats significantly differed from the control group (Jung et al., 2011). DNF-10 was developed as an anti-obesity material and its weight loss effects have been reported previously (Kim et al., 2004; Jung et al., 2009; Jung et al., 2012). It seems that there was a difference in weight gain due to the anti-obesity effect of DNF-10.

\section{Changes in haematological parameters}

The analysis of haematological parameters in whole blood is one of the most common blood tests. In this test, cel- lular components in the blood, such as WBCs and RBCs, are evaluated to determine whether toxicity is caused by orally ingested ingredients. Changes in haematological parameters after single administration of $5,000 \mathrm{mg} / \mathrm{kg}$ DNF-10 and repeated administration of $1,000 \mathrm{mg} / \mathrm{kg}$ were measured to ascertain toxicity (Table 3 ). In the acute toxicity test, the WBC and RBC counts, Hb, Hct, $\mathrm{MCV}, \mathrm{MCH}$, and $\mathrm{MCHC}$ levels among male rats in the experimental group were not significantly different relative to the corresponding parameters in the male controls. For female rats in the experimental group, the RBC count and $\mathrm{Hb}$ level significantly decreased relative to the corresponding parameters in the female controls $(P<0.05)$. However, the parameters remained within the normal range (RBC count, 6.69 8.92; Hb level, 13.1 17.0) (Giknis and Clifford, 2006).

In the subacute toxicity test, the hematologic parameters among male rats in the experimental group were not significantly different relative to the corresponding parameters in the controls (Table 3). However, the WBC and RBC counts, and Hct level for female rats in the experimental group significantly decreased relative to the corresponding values in the control group $(P<0.05)$. The three parameters showed changes within the normal range (WBC count, 3.0 14.3; RBC count, 6.69 8.92; Hct level, 36.9 51.8) (Giknis and Clifford, 2006). The findings obtained for the haematological parameters in both the acute and subacute toxicity tests were within 
Table 3. Haematological parameters of Sprague-Dawley rats treated orally with DNF-10 for the evaluation of acute and subacute toxicity

\begin{tabular}{|c|c|c|c|c|}
\hline \multirow{2}{*}{ Haematological parameters } & \multicolumn{2}{|c|}{ Acute toxicity } & \multicolumn{2}{|c|}{ Subacute toxicity } \\
\hline & Control & DNF-10 & Control & DNF-10 \\
\hline \multicolumn{5}{|l|}{ Female } \\
\hline WBC $\left(10^{3} / \mu \mathrm{L}\right)$ & $6.78 \pm 0.44^{\mathrm{ns}}$ & $5.73 \pm 0.69$ & $6.87 \pm 0.42$ & $5.55 \pm 0.19^{*}$ \\
\hline $\mathrm{RBC}\left(10^{6} / \mu \mathrm{L}\right)$ & $8.30 \pm 0.16$ & $7.81 \pm 0.10^{*}$ & $8.52 \pm 0.16$ & $7.99 \pm 0.12^{*}$ \\
\hline $\mathrm{Hb}(\mathrm{g} / \mathrm{L})$ & $17.93 \pm 0.31$ & $16.68 \pm 0.29^{*}$ & $15.74 \pm 0.27^{\mathrm{ns}}$ & $15.17 \pm 0.14$ \\
\hline Hct $(\%)$ & $54.15 \pm 1.30^{\mathrm{ns}}$ & $51.90 \pm 0.77$ & $53.97 \pm 1.02$ & $50.96 \pm 0.60^{*}$ \\
\hline$M C V(f L)$ & $65.24 \pm 0.57^{\mathrm{ns}}$ & $66.50 \pm 0.55$ & $63.37 \pm 0.34^{\mathrm{ns}}$ & $63.82 \pm 0.53$ \\
\hline $\mathrm{MCH}(\mathrm{pg})$ & $21.63 \pm 0.24^{\mathrm{ns}}$ & $21.36 \pm 0.14$ & $18.52 \pm 0.33^{\text {ns }}$ & $19.01 \pm 0.18$ \\
\hline $\mathrm{MCHC}(\mathrm{g} / \mathrm{dL})$ & $33.16 \pm 0.48^{\mathrm{ns}}$ & $32.13 \pm 0.38$ & $29.23 \pm 0.45^{\mathrm{ns}}$ & $29.77 \pm 0.09$ \\
\hline \multicolumn{5}{|l|}{ Male } \\
\hline WBC $\left(10^{3} / \mu \mathrm{L}\right)$ & $8.83 \pm 0.59^{\text {ns }}$ & $10.83 \pm 0.99$ & $9.58 \pm 0.85^{\mathrm{ns}}$ & $12.17 \pm 1.19$ \\
\hline $\operatorname{RBC}\left(10^{6} / \mu \mathrm{L}\right)$ & $8.57 \pm 0.30^{\text {ns }}$ & $7.88 \pm 0.30$ & $9.32 \pm 0.09^{\text {ns }}$ & $9.37 \pm 0.22$ \\
\hline $\mathrm{Hb}(\mathrm{g} / \mathrm{L})$ & $17.90 \pm 0.47^{\mathrm{ns}}$ & $16.86 \pm 0.65$ & $16.43 \pm 0.26^{\mathrm{ns}}$ & $16.68 \pm 0.40$ \\
\hline Hct (\%) & $59.91 \pm 2.01^{\mathrm{ns}}$ & $56.45 \pm 2.12$ & $58.06 \pm 0.76^{\mathrm{ns}}$ & $58.41 \pm 1.53$ \\
\hline$M C V(f L)$ & $69.96 \pm 0.56^{\mathrm{ns}}$ & $71.73 \pm 0.85$ & $62.31 \pm 0.47^{\mathrm{ns}}$ & $62.31 \pm 0.55$ \\
\hline $\mathrm{MCH}(\mathrm{pg})$ & $20.96 \pm 0.38^{\text {ns }}$ & $21.48 \pm 0.58$ & $17.66 \pm 0.25^{\mathrm{ns}}$ & $17.80 \pm 0.18$ \\
\hline $\mathrm{MCHC}(\mathrm{g} / \mathrm{dL})$ & $29.96 \pm 0.47^{\mathrm{ns}}$ & $29.91 \pm 0.55$ & $28.32 \pm 0.24^{\mathrm{ns}}$ & $28.58 \pm 0.20$ \\
\hline
\end{tabular}

Values are mean \pm SEM for each group.

Significant differences at ${ }^{*} P<0.05$ by Student's $t$-test.

All abbreviations in Table 3 are described in MATERIALS AND METHODS.

${ }^{\mathrm{ns}}$ Not significant.

the normal range and indicated no toxicity of the test compound.

WBC is an essential part of the immune system and is responsible for phagocytic and immune functions. It means a change in the WBC's immune system. RBCs are the main component of blood, and the RBC count is an indicator of abnormalities in hematopoietic function (Park, 2010). DNF-10 is believed to be a safe compound since it did not cause changes to these indicators.

\section{Changes in blood biochemical parameters}

The acute and subacute toxicity of DNF-10 was assessed by analysing blood biochemical parameters in this study (Table 4). In the single-dose toxicity test of DNF-10 (acute toxicity test), the ALT level in male rats of the experimental group was significantly lower than that of male controls $(P<0.05)$. However, the change was within the normal range (ALT level: 26.0 97.0). The BIL level in female rats of the experimental group was significantly lower than that in the female controls. Nevertheless, the change was within the normal range (BIL: 0.2 1.0). Changes in ALT and BIL levels are used as indicators of liver dysfunction (Dodurka and Kraft, 1995). In the acute toxicity test, these indicators showed changes within the normal range and the levels of the other liver function indicators (i.e., AST, ALP, and ALB) were not significantly different between the experimental and control groups.

In the 90-day repeated-dose toxicity test (subacute toxicity test) of DNF-10, the ALB level in male rats of the experimental group increased significantly compared to that of male controls $(P<0.05)$. However, the change was within the normal range (ALB level: 3.70 5.00). The $\mathrm{CRE}$ level in female rats of the experimental group significantly decreased compared to the level for female controls $(P<0.05)$. Nevertheless, the change was within the normal range (CRE level: $0.35 \sim 0.79$ ).

CRE is mainly produced by a non-enzymatic dehydration reaction from creatine in the muscles and is excreted through the kidneys. It is not reabsorbed; therefore, it is used as an indicator of abnormality in kidney function. An increase in the CRE level within the normal range does not indicate DNF-10 toxicity. Another indicator used to evaluate renal function is BUN. It is an indicator of the urea nitrogen level in blood; it is produced when proteins break down in the body. Since it is excreted through the kidneys, the BUN level can indirectly reflect kidney function (Kwon et al., 2003). There was no significant difference in BUN between the experimental and control groups.

In the acute and subacute toxicity tests, intergroup differences in some blood biochemical parameters were significant. Again, the changes in these parameters were within the normal range and did not indicate that the test compound was toxic. Both tests showed no specific abnormalities in body weight, general symptoms, feed intake, negative volume, hematologic examination, and visual findings. In summary, the acute toxicity test, in which $5,000 \mathrm{mg} / \mathrm{kg}$ DNF-10 was orally administered once to Sprague-Dawley rats, and the subacute toxicity test, in which $1,000 \mathrm{mg} / \mathrm{kg}$ DNF-10 was orally administered for 90 days, showed no toxicity. Thus, DNF-10 is believed 
Table 4. Blood biochemical parameters of Sprague Dawley rats treated orally with DNF-10 for the evaluation of acute and subacute toxicity

\begin{tabular}{|c|c|c|c|c|}
\hline \multirow{2}{*}{ Blood biological parameters } & \multicolumn{2}{|c|}{ Acute toxicity } & \multicolumn{2}{|c|}{ Subacute toxicity } \\
\hline & Control & DNF-10 & Control & DNF-10 \\
\hline \multicolumn{5}{|l|}{ Female } \\
\hline ALB $(g / d L)$ & $4.61 \pm 0.10^{\mathrm{ns}}$ & $4.47 \pm 0.10$ & $5.27 \pm 0.09^{\text {ns }}$ & $5.54 \pm 0.12$ \\
\hline $\operatorname{ALT}(\mathrm{U} / \mathrm{L})$ & $31.00 \pm 1.18^{\mathrm{ns}}$ & $32.78 \pm 1.93$ & $33.00 \pm 4.80^{\mathrm{ns}}$ & $35.22 \pm 4.44$ \\
\hline AST (U/L) & $76.56 \pm 2.66^{\mathrm{ns}}$ & $73.78 \pm 2.64$ & $86.11 \pm 15.82^{\mathrm{ns}}$ & $80.22 \pm 14.83$ \\
\hline $\mathrm{BIL}(\mathrm{mg} / \mathrm{dL})$ & $0.49 \pm 0.03$ & $0.38 \pm 0.03^{*}$ & $0.42 \pm 0.02^{\mathrm{ns}}$ & $0.36 \pm 0.03$ \\
\hline $\mathrm{BUN}(\mathrm{mg} / \mathrm{dL})$ & $17.43 \pm 0.83^{\mathrm{ns}}$ & $16.79 \pm 0.92$ & $17.03 \pm 0.82^{\mathrm{ns}}$ & $17.38 \pm 0.72$ \\
\hline CPK (U/L) & $165.44 \pm 32.11^{\mathrm{ns}}$ & $136.89 \pm 15.33$ & $63.00 \pm 2.45^{\mathrm{ns}}$ & $54.89 \pm 2.99$ \\
\hline CRE (mg/dL) & $0.36 \pm 0.02^{\text {ns }}$ & $0.38 \pm 0.02$ & $0.46 \pm 0.03$ & $0.35 \pm 0.02^{* *}$ \\
\hline GLU (mg/dL) & $134.44 \pm 12.98^{\mathrm{ns}}$ & $162.56 \pm 21.63$ & $211.22 \pm 15.13^{\mathrm{ns}}$ & $225.89 \pm 10.36$ \\
\hline $\mathrm{HDL}(\mathrm{mg} / \mathrm{dL})$ & $54.67 \pm 4.00^{\mathrm{ns}}$ & $60.89 \pm 3.19$ & $61.00 \pm 3.47^{\mathrm{ns}}$ & $58.00 \pm 3.00$ \\
\hline $\mathrm{LDH}(\mathrm{U} / \mathrm{L})$ & $235.00 \pm 20.24^{\text {ns }}$ & $236.78 \pm 36.17$ & $175.00 \pm 8.85^{\text {ns }}$ & $157.22 \pm 19.69$ \\
\hline $\mathrm{NH}_{3}(\mu \mathrm{g} / \mathrm{dL})$ & $428.89 \pm 54.57^{\text {ns }}$ & $479.56 \pm 32.67$ & $355.44 \pm 28.35^{\mathrm{ns}}$ & $342.00 \pm 25.59$ \\
\hline $\mathrm{TCHO}(\mathrm{mg} / \mathrm{dL})$ & $80.33 \pm 6.78^{\text {ns }}$ & $84.11 \pm 5.94$ & $143.78 \pm 8.70^{\text {ns }}$ & $146.44 \pm 5.44$ \\
\hline $\mathrm{TP}(\mathrm{g} / \mathrm{dL})$ & $6.33 \pm 0.10^{\mathrm{ns}}$ & $6.12 \pm 0.07$ & $7.38 \pm 0.14^{\mathrm{ns}}$ & $7.56 \pm 0.14$ \\
\hline TG (mg/dL) & $43.44 \pm 3.46^{\mathrm{ns}}$ & $47.44 \pm 5.20$ & $82.11 \pm 11.79^{\mathrm{ns}}$ & $66.11 \pm 7.89$ \\
\hline UA (mg/dL) & $3.78 \pm 0.23^{\mathrm{ns}}$ & $4.32 \pm 0.17$ & $4.53 \pm 0.29^{\text {ns }}$ & $4.70 \pm 0.24$ \\
\hline \multicolumn{5}{|l|}{ Male } \\
\hline ALB (g/dL) & $4.40 \pm 0.06^{\mathrm{ns}}$ & $4.38 \pm 0.08$ & $4.28 \pm 0.08$ & $4.53 \pm 0.06^{*}$ \\
\hline ALT (U/L) & $47.89 \pm 2.49$ & $40.56 \pm 0.75^{*}$ & $29.78 \pm 1.41^{\mathrm{ns}}$ & $33.78 \pm 1.09$ \\
\hline AST (U/L) & $74.89 \pm 2.81^{\mathrm{ns}}$ & $72.00 \pm 2.16$ & $63.67 \pm 4.64^{\mathrm{ns}}$ & $77.78 \pm 5.08$ \\
\hline BIL (mg/dL) & $0.34 \pm 0.03^{\mathrm{ns}}$ & $0.30 \pm 0.02$ & $0.26 \pm 0.20^{\mathrm{ns}}$ & $0.20 \pm 0.02$ \\
\hline $\operatorname{BUN}(\mathrm{mg} / \mathrm{dL})$ & $18.16 \pm 0.77^{\mathrm{ns}}$ & $17.96 \pm 0.59$ & $19.90 \pm 1.42^{\mathrm{ns}}$ & $17.61 \pm 1.12$ \\
\hline CPK (U/L) & $103.67 \pm 8.68^{\text {ns }}$ & $108.89 \pm 10.65$ & $82.33 \pm 20.35^{\mathrm{ns}}$ & $139.33 \pm 17.89$ \\
\hline CRE $(\mathrm{mg} / \mathrm{dL})$ & $0.36 \pm 0.02^{\mathrm{ns}}$ & $0.34 \pm 0.03$ & $0.36 \pm 0.02^{\text {ns }}$ & $0.32 \pm 0.01$ \\
\hline $\mathrm{GLU}(\mathrm{mg} / \mathrm{dL})$ & $220.44 \pm 20.77^{\text {ns }}$ & $237.67 \pm 26.44$ & $374.67 \pm 25.03^{\text {ns }}$ & $327.22 \pm 23.66$ \\
\hline $\mathrm{HDL}(\mathrm{mg} / \mathrm{dL})$ & $52.67 \pm 1.87^{\mathrm{ns}}$ & $47.67 \pm 2.15$ & $75.44 \pm 3.59^{\text {ns }}$ & $78.78 \pm 2.80$ \\
\hline $\mathrm{LDH}(\mathrm{U} / \mathrm{L})$ & $154.67 \pm 19.47^{\mathrm{ns}}$ & $141.56 \pm 15.47$ & $183.86 \pm 38.47^{\text {ns }}$ & $195.60 \pm 12.39$ \\
\hline $\mathrm{NH}_{3}(\mu \mathrm{g} / \mathrm{dL})$ & $462.89 \pm 35.52^{\mathrm{ns}}$ & $463.11 \pm 28.99$ & $381.67 \pm 23.50^{\mathrm{ns}}$ & $335.89 \pm 35.58$ \\
\hline $\mathrm{TCHO}(\mathrm{mg} / \mathrm{dL})$ & $87.33 \pm 2.92^{\text {ns }}$ & $80.67 \pm 2.50$ & $104.89 \pm 6.20^{\text {ns }}$ & $105.33 \pm 6.74$ \\
\hline $\mathrm{TP}(\mathrm{g} / \mathrm{dL})$ & $6.22 \pm 0.08^{\mathrm{ns}}$ & $6.16 \pm 0.09$ & $6.43 \pm 0.09^{\text {ns }}$ & $6.33 \pm 0.53$ \\
\hline TG (mg/dL) & $58.89 \pm 4.71^{\mathrm{ns}}$ & $60.11 \pm 1.90$ & $55.33 \pm 5.07^{\text {ns }}$ & $54.11 \pm 3.39$ \\
\hline UA (mg/dL) & $5.34 \pm 0.28^{n s}$ & $5.32 \pm 0.17$ & $6.90 \pm 0.53^{\mathrm{ns}}$ & $6.20 \pm 0.63$ \\
\hline
\end{tabular}

Values are mean \pm SEM for each group.

Significant differences at ${ }^{*} P<0.05$ and ${ }^{* *} P<0.01$, respectively by Student's $t$-test.

All abbreviations in Table 4 are described in MATERIALS AND METHODS.

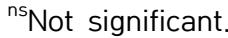

to be a safe material that is non-toxic at the dosages employed in our study.

\section{AUTHOR DISCLOSURE STATEMENT}

The authors declare no conflict of interest.

\section{REFERENCES}

Bekatorou A, Psarianos C, Koutinas AA. Production of food grade yeasts. Food Technol Biotechnol. 2006. 44:407-415.

Dodurka T, Kraft W. Alanine aminotransferase (ALT), aspartate aminotransferase (AST), glutamate dehydrogenase (GLDH), alkaline phosphatase (AP) and gamma-glutamyltransferase (GGP) in intestinal diseases of dogs. Berl Munch Tierarztl
Wochenschr. 1995. 108:244-248.

Giknis MLA, Clifford CB. Clinical laboratory parameters for $\mathrm{Crl}$ : CD (SD) rats. Charles River Laboratories, Wilmington, MA, USA. 2006. p 1-14.

Hong JW, Kim IH, Yoo SH, Lee HS, Kwon OS, Min BJ, et al. The effects of yeast hydrolysate SCP-20 on reproductive function in male mice. J Korean Soc Food Sci Nutr. 2004. 33:451-454.

Jung EY, Hong YH, Kim JH, Park Y, Bae SH, Chang UJ, et al. Effects of yeast hydrolysate on hepatic lipid metabolism in highfat-diet-induced obese mice: yeast hydrolysate suppresses body fat accumulation by attenuating fatty acid synthesis. Ann Nutr Metab. 2012. 61:89-94.

Jung EY, Kang DH, Suh HJ, Chang UJ. Effects of yeast hydrolysate on neuropeptide Y (NPY) and tryptophan hydroxylase (TPH) immunoreactivity in rats. Phytother Res. 2009. 23:619-623.

Jung EY, Lee HS, Chang UJ, Bae SH, Kwon KH, Suh HJ. Acute and subacute toxicity of yeast hydrolysate from Saccharomyces cerevisiae. Food Chem Toxicol. 2010. 48:1677-1681.

Jung EY, Park SS, Kim JH, Chang UJ, Bae SH, Choi JW, et al. Safety study of yeast hydrolysate with below $10 \mathrm{kDa}$ molecular weight 
in animal models. J Health Sci. 2011. 57:532-539.

Kim JM, Lee SW, Kim KM, Chang UJ, Song JC, Suh HJ. Anti-stress effect and functionality of yeast hydrolysate SCP-20. Eur Food Res Technol. 2003. 217:168-172.

Kim KM, Chang UJ, Kang DH, Kim JM, Choi YM, Suh HJ. Yeast hydrolysate reduces body fat of dietary obese rats. Phytother Res. 2004. 18:950-953.

Kwon MA, Kim GS, Hong JK, Jo HS, Kim JK, Yang MK, et al. The effects of $0.45 \%$ and $0.9 \%$ saline solutions on serum sodium concentrations in chronic renal failure patients. Korean J Anesthesiol. 2003. 44:462-468.

Lazo-Vélez MA, Serna-Saldívar SO, Rosales-Medina MF, TinocoAlvear M, Briones-García M. Application of Saccharomyces cerevisiae var. boulardii in food processing: a review. J Appl Microbiol. 2018. 125:943-951.

OECD. Test no. 408: Repeated dose 90-day oral toxicity study in rodents: OECD Guidelines for the Testing of Chemicals, Section 4. OECD Publishing, Paris, France. 2018 [cited 01 Feb 2020]. Available from: https://doi.org/10.1787/9789264070 707-en

OECD. Test no. 423: Acute oral toxicity-acute toxic class method. OECD Guidelines for the Testing of Chemicals, Section 4. OECD Publishing, Paris, France. 2002 [cited 01 Feb 2020].
Available from: https://doi.org/10.1787/9789264071001-en Ozuna C, Paniagua-Martínez I, Castaño-Tostado E, Ozimek L, Amaya-Llano SL. Innovative applications of high-intensity ultrasound in the development of functional food ingredients: production of protein hydrolysates and bioactive peptides. Food Res Int. 2015. 77:685-696.

Parapouli M, Vasileiadis A, Afendra AS, Hatziloukas E. Saccharomyces cerevisiae and its industrial applications. AIMS Microbiol. 2020. 6:1-31.

Park SK. An interpretation on abnormal finding of CBC. Korean J Med. 2010. 78:531-539.

Suh HJ, Kim SY, Chang UJ, Kim JM. Anti-stress effects of chewing gum prepared with yeast hydrolysate. Eur Food Res Technol. 2008. 227:331-336.

Verduyn C, Suksomcheep A, Suphantharika M. Effect of high pressure homogenization and papain on the preparation of autolysed yeast extract. World J Microbiol Biotechnol. 1999. 15:5763.

Yu KW, Kim JM, Oh SH, Chang UJ, Suh HJ. Physiological effects of yeast hydrolysate SCP-20. Food Res Int. 2002. 35:879-884.

Yu KW, Oh SH, Choi YS, Hwang WJ, Suh HJ. The reduction effect of yeast hydrolysate SCP-20 on premenstrual syndrome. J Korean Soc Food Sci Nutr. 2001. 30:1000-1003. 